\title{
Análise comparativa da imunoexpressão da proteína p53 (clones D0-7 e PAb-240) em carcinomas de células escamosas intrabucais e labiais
}

\author{
Comparative analysis of p53 protein immunostaining (antibodies D0-7 and PAb-240) in oral cavity and lip \\ squamous cell carcinomas
}

José de Assis Silva Júnior1; Vagner Gonçalves Bernardo²; Karen Zavaro Balassiano33; Flávia Dantas Soares4; Eliene Carvalho da Fonseca5; Licínio Esmeraldo da Silva ${ }^{6}$; Simone de Queiroz Chaves Lourenço ${ }^{7}$

\section{unitermos}

Carcinoma de células escamosas

Câncer oral

Imuno-histoquímica

Proteína supressora de tumor $\mathrm{p} 53$

\section{resumo}

Introdução: A carcinogênese caracteriza-se como um processo multifatorial, e a inativação da proteína p53 é uma alteração genética comumente observada nos carcinomas de células escamosas de boca (CCEB). Objetivo: Analisar e comparar a imunoexpressão da proteína p53, por meio dos clones DO-7 e PAb-240, em CCEB com localização intrabucal e em lábio inferior. Material e métodos: Foram selecionados 40 casos de CCEB, sendo 20 de localização intrabucal e 20 em lábio inferior. Foi realizado um estudo imuno-histoquímico utilizando os anticorpos anti-p53 clone DO-7 e PAb-240. A imunoquantificação foi realizada por meio de análise digital de imagem, e os resultados, submetidos a tratamentos estatísticos. Resultados: A imunoexpressão da proteína p53 foi verificada com o anticorpo DO-7 em 13 casos (65\%) de carcinoma intrabucal e em 19 (95\%) de carcinoma de lábio inferior. Imunorreatividade para o anticorpo PAb-240 foi observada em 9 casos (45\%) de lesões intrabucais e em 15 (75\%) localizados em lábio inferior. Não foram observadas, segundo o teste de Mann-Whitney, diferenças estatisticamente significativas $(p>0,05)$ na expressão da proteína $p 53$ entre as duas localizações estudadas, independentemente do anticorpo avaliado. Foram identificadas, pelo teste de Wilcoxon, diferenças estatisticamente significativas entre a expressão dos clones DO-7 e PAb-240 em cada um dos grupos analisados (valor $p=0,013$ - lábio inferior; valor $p=0,016$-intrabucal). Conclusões: A expressão da proteína p53 observada nos CCEB, com localizações intrabucais e labiais, sugere a ocorrência de mutações no gene TP53. As diferenças quantitativas obtidas entre os anticorpos estudados, independentemente da localização das lesões, refletem uma especificidade distinta entre os clones DO-7 e PAb-240. O desenvolvimento de mais estudos será fundamental para estabelecer o anticorpo mais adequado para proteína p53 em CCEB.

\section{abstract}

Background: Carcinogenesis is a multifactorial process and inactivation of 553 protein is a genetic change commonly observed in oral squamous cell carcinomas (OSCC). Objectives: To analyze and compare the expression of p53 protein through antibodies DO-7 and PAb-240 in OSCC samples located in the oral cavity and lower lip. Material and methods: Forty cases of OSCC were selected and divided into oral cavity and lower lip groups (20 cases each). Immunohistochemical technique was performed using antibodies DO-7 and PAb-240. Quantification of the cases was performed through digital image analysis and underwent specific statistical treatments. Results: Expression of p53 protein was verified with DO-7 antibody in 13 cases (65\%) of oral cavity carcinomas and in 19 cases (95\%) of lower lip carcinoma. PAb-240 positivity was detected in 9 cases (45\%) of oral cavity lesions and in 15 cases (75\%) located in the lower lip. According to Mann-Whitney test, there were no statistically significant differences between the expressions of 553 protein in both groups, regardless of the antibody used. According to Wilcoxon test, there were statistically significant differences between the expression of DO-7 antibody and PAb-240 in each of the analyzed groups ( $\mathrm{p}$-value $=0.013$; lower lip $\mathrm{p}$-value $=0.016$ - oral cavity). Conclusions: The expression of 553 protein was observed both in the oral cavity and lip OSCC, which suggests the occurrence of mutations in TP53 gene. The quantitative differences between the antibodies studied, regardless of the site of the lesions, reflect different specificity between clones DO-7 and PAb-240. Further studies are required to establish the best antibody for 553 protein in oral squamous cell carcinomas.

\section{key words}

Squamous cell carcinoma

Oral cancer

Immunohistochemistry

Tumor suppressor protein p53

1. Mestre em Patologia pela Universidade Federal Fluminense (UFF).

2. Mestre em Patologia pela UFF.

3. Doutora em Patologia pela Faculdade de Odontologia de Bauru da Universidade de São Paulo (FOB/USP).

4. Mestre em Patologia pela UFF.

5. Mestre em Biologia Celular e Molecular pelo Instituto Oswaldo Cruz (IOC); professora adjunta do Departamento de Patologia da UFF.

6. Mestre em Sistema de Cestão pela UFF; professor adjunto do Departamento de Estatística da UFF.

7. Doutora em Patologia pela Faculdade de Odontologia de Bauru (FOB/USP);

professora adjunta do Departamento de Patologia da UFF. 


\section{Introdução}

O câncer de boca representa cerca de $3 \%$ de todas as neoplasias malignas nos homens e $2 \%$ nas mulheres, segundo a Sociedade Americana de Câncer $(S A C)^{(30)}$. No Brasil, está entre os dez tipos de câncer mais frequentes, constituindo-se em um problema de saúde pública. A estimativa de incidência desse tipo de câncer para 2008 aponta esse tumor como o sexto mais comum entre os homens (com 10.380 casos estimados) e o sétimo entre as mulheres (com 3.780 casos estimados) (22).

O carcinoma de células escamosas (CCE) compreende cerca de $90 \%$ de todas as neoplasias malignas da boca, sendo a língua, o lábio inferior e o assoalho bucal os sítios frequentemente afetados $(10,20,30)$. O local de acometimento desses tumores deve ser considerado um importante indicador de prognóstico, uma vez que os localizados em lábio inferior exibem melhores prognósticos, quando comparado com as demais localizações intrabucais ${ }^{(2,9)}$. Tal fato pode estar associado à exposição a fatores etiológicos distintos; os localizados em lábio estão estritamente relacionados com os níveis de exposição à radiação ultravioleta, enquanto aqueles localizados em regiões intrabucais estão frequentemente associados ao tabagismo e ao etilismo ${ }^{(29,30,32)}$.

O gene supressor de tumor TP53, descrito primeiramente em $1979(7,24,25)$, codifica a proteína p53, que age como fator de transcrição com importantes funções na regulação do ciclo celular e indução da apoptose, em decorrência a danos no DNA ${ }^{(4,31,46)}$. Em tecidos normais, a proteína selvagem está expressa em baixas concentrações, fato que pode ser justificado pela sua meia-vida curta, sendo sua presença raramente detectada pela técnica de imuno-histoquímica ${ }^{(17,31)}$.

Mutações no gene TP53 são alterações moleculares comuns nos $\mathrm{CCE}^{(17,31,47)}$; no entanto, estudos têm demonstrado um padrão de mutação distinto associado a fatores etiológicos específicos ${ }^{(32,35)}$. Consequentemente, a localização do câncer de boca pode determinar diferentes padrões de mutação, como o encontrado nos CCE de lábio e intrabu-

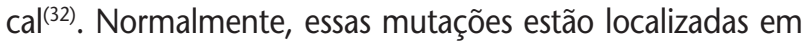
domínios específicos da proteína p53(37), ocorrendo com maior frequência no domínio hidrofóbico de ligação ao $\mathrm{DNA}^{(8,43)}$. Apenas $5 \%$ das mutações acometem as regiões $\mathrm{N}$-terminal e C-terminal e, quando ocorrem, podem não alterar a conformação da proteína ${ }^{(8,14)}$.

Diferentes anticorpos monoclonais estão disponíveis para avaliação da expressão da proteína p53 na espécie humana, representados por clones específicos que reconhecem diferentes epítopos localizados entre as quatro regiões funcionais principais da proteína $\mathrm{p} 53^{(3,16,27,45)}$, sendo a maioria dos anticorpos direcionada a epítopos situados na região $\mathrm{N}$-terminal da proteína. Para investigar sua estrutura funcional, assim como estabelecer comparações entre a proteína selvagem e a mutante ${ }^{(48)}$, a escolha correta do anticorpo pode definir a expressão da proteína nos tecidos, assegurando a sensibilidade e reprodutibilidade dos resultados ${ }^{(42)}$.

Clones como o DO-7 são capazes de se ligarem na conformação nativa e mutada da proteína, enquanto outros, como o PAb-240, reagem somente com a proteína p53 mutante. O anticorpo PAb-240 apresenta especificidade na identificação de uma sequência específica localizada na região de ligação do $D N A^{(40)}$, frequentemente alterada nas neoplasias malignas ${ }^{(8,43)}$, incluindo as que acometem a boca ${ }^{(11,17,47)}$

Considerando que a maioria das investigações utiliza o anticorpo clone DO-7, em que a imunopositividade pode refletir um aumento da expressão da proteína p53 nativa e/ou mutada e que outras sequências da estrutura proteica são mais associadas à presença de mutações nas neoplasias malignas (como a identificada pelo clone PAb-240), justificase a realização de mais estudos. Este trabalho teve como objetivo analisar e comparar a imunoexpressão da proteína p53, por meio dos clones DO-7 e PAb-240, em carcinomas de células escamosas de boca (CCEB), com localização intrabucal e em lábio inferior.

\section{Material e métodos}

\section{Amostra}

Foram selecionados 40 casos de CCEB, provenientes de biópsias incisionais, diagnosticados no arquivo do Serviço de Anatomia Patológica (SAP) do Hospital Universitário Antônio Pedro da Universidade Federal Fluminense (HUAP/UFF). A amostra foi dividida em dois grupos de acordo com a localização: intrabucal (grupo I) e em lábio inferior (grupo II). A partir dos laudos histopatológicos, foram coletados os seguintes dados clínicos: sexo, idade e localização anatômica. O critério de seleção da amostra foi de material exibindo histopatologia característica, livre de artefatos, bem preservado e com quantidade suficiente para realização de recortes. As amostras coradas pela técnica de hematoxilina e eosina (HE) foram 
avaliadas segundo o grau de diferenciação determinado pela Organização Mundial da Saúde (OMS)(1).

\section{Técnica de imuno-histoquímica}

A técnica imuno-histoquímica foi realizada no Laboratório de Imuno-histoquímica do SAP-HUAP/UFF para detecção da proteína p53, utilizando os anticorpos monoclonais obtidos de camundongo anti-p53 clone DO-7 (DAKOCytomation - EUA, classe lgG2b, 1:200, código M7001) e anti-p53 clone PAb-240 (DAKOCytomation - EUA, classe IgG1, 1:300, código M3566), por meio da técnica da estreptavidina-biotina-imunoperoxidase. Para cada bloco, foram realizados cortes histológicos seriados de $4 \mu \mathrm{m}$ de espessura, estendidos em lâminas previamente tratadas com substância adesiva (3-aminopropil-trietoxi silano, SIGMA - USA). Os cortes obtidos foram desparafinizados em xilol e reidratados em soluções de álcool etílico.

O bloqueio da peroxidase endógena foi obtido por meio da imersão das lâminas em solução de peróxido de hidrogênio (P.A.) a 3\% diluído em água destilada durante 30 minutos. Para a recuperação antigênica em banho-maria, utilizou-se a solução comercial da DAKO de pH 6 (Target antigen retrieval solution 10X concentrate, código S1699 DAKOCytomation - EUA) para o anticorpo anti-p53 clone DO-7 e solução comercial da DAKO de pH 9,9 (Target antigen retrieval solution High $\mathrm{pH} 10 \mathrm{X}$ concentrate, código S3307 DAKOCytomation - EUA) para o anticorpo monoclonal anti-p53 clone PAb-240. Esse protocolo foi estabelecido após inúmeros testes realizados previamente.

Posteriormente, as secções foram incubadas com anticorpo primário em overnight a $4^{\circ} \mathrm{C}$. Finalizado o tempo de incubação com os anticorpos primários, os cortes foram imersos em solução tampão TBS-T (800 ml de ácido clorídrico $1 \mathrm{~N} ; 116 \mathrm{~g}$ de NaCl; $122 \mathrm{~g}$ de hidroxil-metil-aminometano, $10 \mathrm{ml}$ de Tween 20; completando para $20 \mathrm{I}$ de água destilada; $0,05 \mathrm{M} / \mathrm{pH} 7,4$ ) e submetidos à incubação com o complexo estreptavidina-biotina (LSAB + System, HRP, código K0690, DAKOCytomation - EUA). O anticorpo secundário biotinilado foi aplicado sobre os cortes, permanecendo por 30 minutos em câmara umidificadora à temperatura ambiente, seguido por dois banhos em solução tampão TBS-T, cada um por cinco minutos. Em sequência, aplicou-se a estreptavidina sobre os cortes, aguardando-se mais 30 minutos nas mesmas condições. Posteriormente, as lâminas foram lavadas em solução tampão TBS-T e reveladas com o substrato cromógeno diaminobenzidina (Liquid DAB + substrate, Chromogen System, código
K3468, DAKOCytomation - EUA). Após essa etapa, as lâminas foram lavadas com água destilada e contracoradas com hematoxilina de Harris. Cortes de um caso de CCEB previamente positivo para os anticorpos empregados foram utilizados como controle positivo. O controle negativo foi obtido pela substituição do anticorpo primário pela mesma solução usada para diluir os anticorpos (Antibody Diluent with background Reducing components, código \$3022 DAKOCytomation - EUA), conforme procedimento imunohistoquímico usual do referido laboratório.

\section{Análise quantitativa}

A quantificação da marcação obtida pela técnica de imuno-histoquímica foi realizada por meio de análise digital de imagem, usando a mesma metodologia empregada no trabalho de Camisasca et al. ${ }^{(5)}$, com o auxílio do Programa Image ProPlus 4.5 (Media Cybernetics, Silver Spring, EUA). De cada caso, um total de cinco campos foi capturado, selecionando-se áreas de maior imunopositividade e utilizando-se a objetiva de 20x. O índice de área foi determinado pela razão entre a área imunopositiva quantificada e a área tumoral total previamente delimitada.

\section{Análise estatística}

Os dados dos índices de área foram descritos por meio dos parâmetros média ( \pm desvio padrão) e número de casos. Comparação entre os índices de área, tanto pelo clone DO-7 quanto pelo PAb-240 nos dois grupos avaliados, foi realizada pelo teste de Mann-Whitney, e a comparação entre os índices de área de cada marcador foi realizada pelo teste de Wilcoxon. O nível de significância das decisões estatísticas foi de 0,05 (5\%) e a análise estatística foi apoiada pelo programa Statistical Package of Social Science (SPSS) versão 10.0.

\section{Resultados}

O perfil da amostra, de acordo com as variáveis gênero, idade, localização e gradação histopatológica, está descrito nas Tabelas 1 e $\mathbf{2}$.

Foi observada expressão da proteína p53 no núcleo das células epiteliais tumorais (coloração acastanhada), para os anticorpos clones DO-7 e PAb-240 (Figuras 1 e 2). 


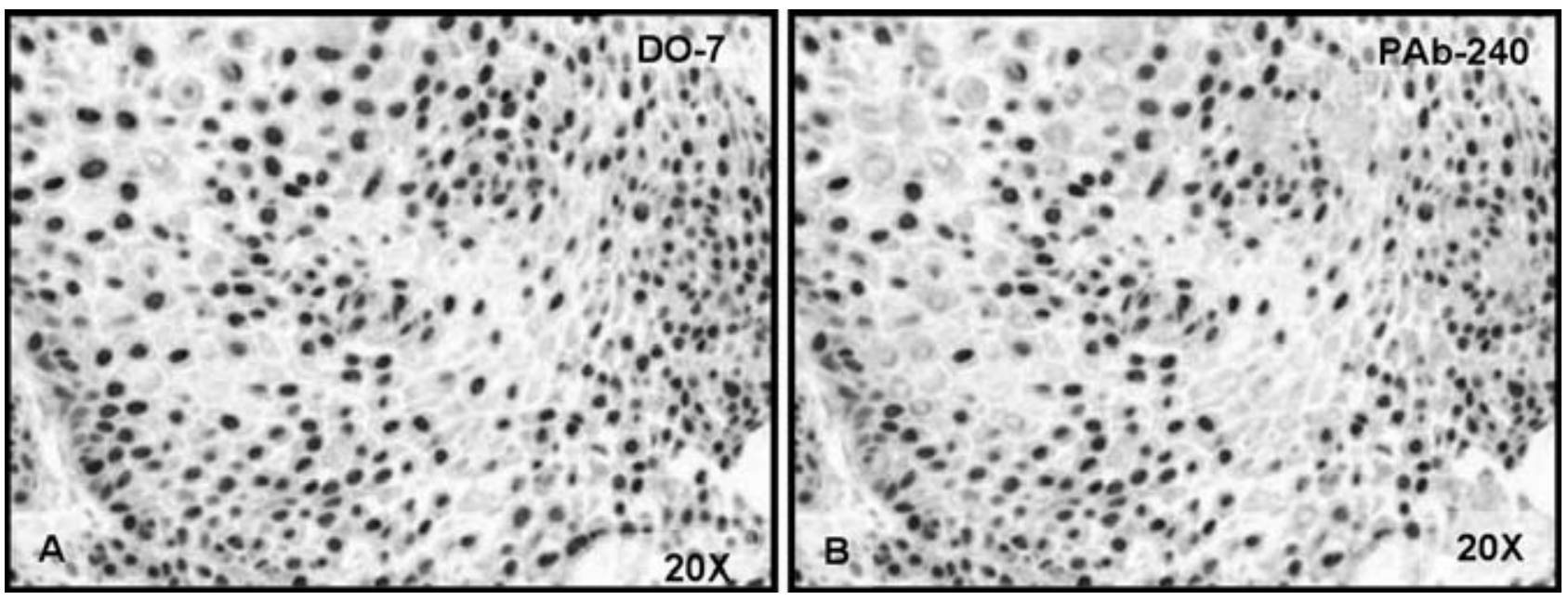

Figura 1 - Carcinomas de células escamosas com localização intrabucal. A. Expressão nuclear da proteína p53 por meio do anticorpo monoclonal clone DO-7. B. Imunoexpressão da proteína p53, exibindo marcações nucleares nas células tumorais, representada pelo clone PAb-240. (Estreptavidina-biotina-imunoperoxidase, objetiva de 20X)

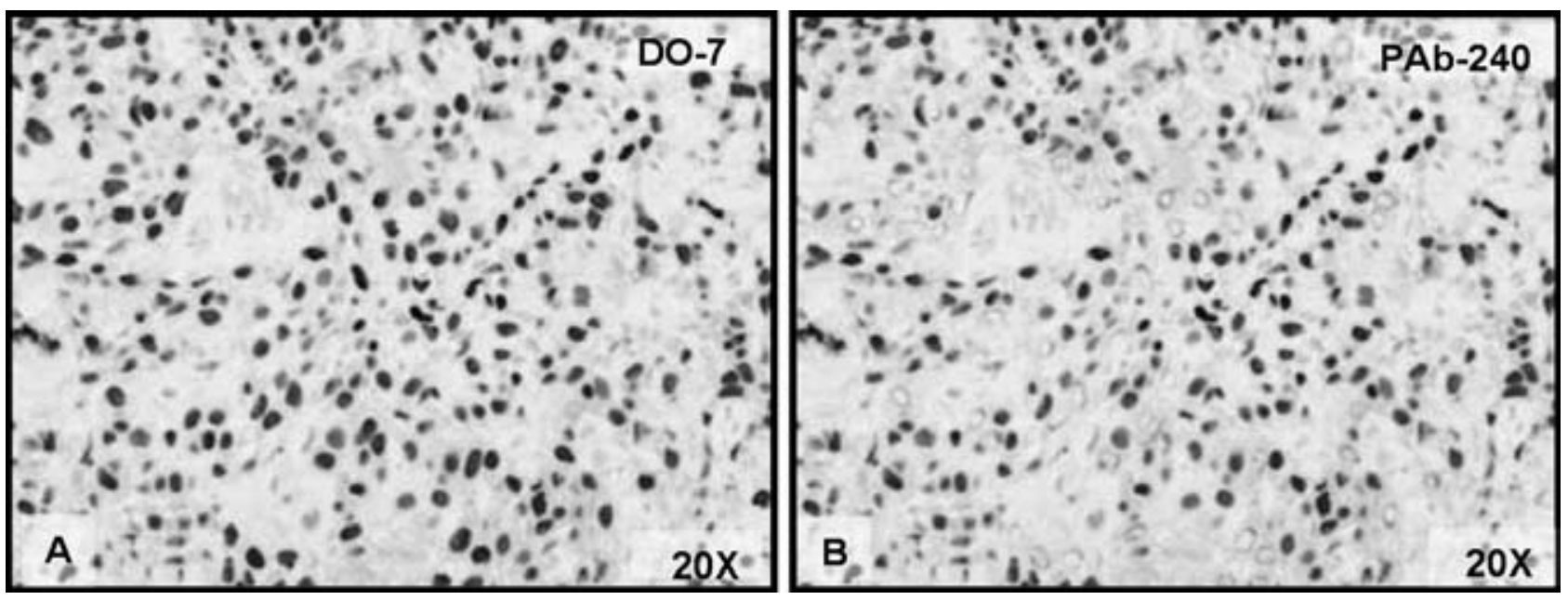

Figura 2 - Carcinomas de células escamosas localizados em lábio inferior. A. Expressão nuclear da proteína p53 representada pelo anticorpo monoclonal clone DO-7. B. Imunolocalização da proteína p53, mostrando o padrão nuclear, representada pelo clone PAb-240. (Estreptavidina-biotina-imunoperoxidase, objetiva de 20X)

\section{Discussão}

O gene TP53 é considerado um dos principais genes associados à supressão tumoral por desempenhar importantes funções nos processos fisiológicos e patológicos $38,44,46)$. Apresenta-se comumente mutado em diversas neoplasias malignas, incluindo as que acometem a boca ${ }^{(11,37,47)}$.

Diversas são as técnicas que estão disponíveis para o estudo de alterações na molécula p53, incluindo a análise de mutação desse gene, assim como a expressão da proteína ${ }^{(31)}$. Mutações no gene TP53 podem alterar a função da proteína codificada, acarretando um aumento na sua meia-vida biológica (normalmente curta), podendo assim ser identificada pela técnica da imuno-histoquímica ${ }^{(17,31)}$. Essa técnica tem grande aplicação na rotina diagnóstica e na pesquisa científica. Inúmeros estudos utilizam essa me- todologia para avaliar a expressão da proteína p 53 no CCEB em busca por biomarcadores prognósticos $(2,6,12,23,33,34)$.

A técnica da imuno-histoquímica pode fornecer dados limitados quando se deseja avaliar a expressão da proteína p53 na carcinogênese bucal, apresentando uma discordância de aproximadamente $40 \%$ quando comparada à técnica de sequenciamento do $D N A^{(26,41)}$. O acúmulo dessa proteína pode ocorrer devido a outros fatores, como associação com proteínas virais, falhas na sua degradação, ou até mesmo ser identificada em sua função biológica normal, gerando resultados falso-positivos ${ }^{(13,31)}$. Sendo assim, considerações técnicas, como escolha do anticorpo, fixação do tecido e protocolo de recuperação antigênica, podem interferir no padrão da imunopositividade, influenciando os resultados obtidos ${ }^{(28)}$.

O tabaco e o álcool estão bem estabelecidos como fatores etiológicos exógenos no desenvolvimento e na 
progressão dos carcinomas intrabucais; diferentemente, os carcinomas localizados em lábio inferior recebem bastante influência da exposição à radiação solar ${ }^{(29,30,32)}$. Dessa forma, a amostra desse estudo foi dividida em dois grupos, de acordo com sua localização (intrabucal e lábio inferior).

No presente estudo, observou-se a expressão da proteína p53 nos carcinomas com localização em lábio inferior em 19 casos (95\%) quando utilizado o clone DO-7 e em 15 casos (75\%) para o PAb-240. Em um estudo conduzido por Horta et al.(21), foi avaliada uma série de 21 carcinomas de lábio, obtendo-se expressão positiva da proteína p53, verificada pelo clone DO-1 em 85,7\% dos casos avaliados. Em uma análise de 79 carcinomas de lábio, Garcia-Montesinos-Perea et al. ${ }^{(16)}$ verificaram imunopositividade para a proteína p53 por meio do clone DO-7 em 70,6\% dos casos. Em relação aos casos com localização intrabucal, foi observado nesse estudo expressão positiva da proteína p53 em 13 casos (65\%) para o anticorpo DO-7 e em 9 casos (45\%), para o PAb-240. Cruz et al. ${ }^{(11)}$, em uma análise de carcinomas intrabucais, verificaram a expressão da proteína p53 em 33 casos (60\% dos avaliados), utilizando o anticorpo DO-7. Estudos realizados por Schoelch et al.(36), em uma amostra de 35 casos de CCEB intrabucais, observaram imunopositividade para p53, utilizando o anticorpo DO-7 em 18 casos (51,4\%). Quando comparados aos trabalhos similares descritos na literatura, os resultados imuno-histoquímicos obtidos nesse estudo mostraram percentuais de imunopositividade semelhantes, embora haja divergências no perfil da amostras, nos protocolos imuno-histoquímicos, nos anticorpos selecionados e na forma de análise dos resultados obtidos.

A expressão da proteína p53 em ambos os clones avaliados predominou nos casos de carcinomas de lábio inferior (DO-7 - 95\%, PAb-240 - 75\%) em relação aos intrabucais (DO-7 - 65\%, PAb-240 - 45\%), porém sem diferença estatisticamente significativa quando os índices de área foram comparados. Com objetivo de avaliar mutações no gene TP53 em câncer de lábio e com localização intrabucal, Ostwald et al. ${ }^{(32)}$ verificaram que a presença e o tipo de mutações desse gene estão associados às diferenças de localização da lesão, estando a radiação solar relacionada com um tipo específico de mutação, com padrão diferente dos CCE intrabucais, em que se observou estreita relação com o tabaco. Dessa maneira, a localização dos tumores que afetam a boca deve ser considerada no estudo da molécula p53. Outro ponto que deve ser valorizado no desenho do estudo e que pode influenciar nos resultados são as condições sociocultural e geográfica da população em análise ${ }^{(35,38)}$.
Embora existam diversos trabalhos na literatura que correlacionam a expressão da proteína p53 nos CCEB, a maioria utiliza o anticorpo monoclonal anti-p53 DO-7, que reconhece a proteína em sua conformação selvagem e mutada, identificando um epítopo localizado entre os aminoácidos 21 a $25^{(39)}$. Neste estudo, foram incluídos os clones DO-7 e PAb-240 por reconhecerem domínios específicos e distintos da proteína p53, com a finalidade de avaliar e comparar suas expressões em CCEB. O anticorpo monoclonal PAb-240 reconhece um epítopo altamente conservado entre as espécies, localizado em humanos, entre os aminoácidos 213 a $217^{(40)}$ com especificidade somente para a conformação mutada da proteína $\mathrm{p} 53^{(15)}$.

Ao comparar a expressão da proteína utilizando-se dois marcadores direcionados a diferentes epítopos da proteína p53, foram verificadas diferenças quantitativas de marcação nos anticorpos estudados. A marcação foi mais evidente com o anticorpo DO-7 quando comparado ao PAb-240 $(p>0,05)$ independentemente do grupo de lesão, o que vai de encontro aos trabalhos de Gonzalez-Moles et al., ${ }^{(18)}$ e Harlozinska et al., ${ }^{(19)}$ em estudos desenvolvidos em líquen plano oral e carcinomas de ovário, respectivamente. Jayasurya et al. ${ }^{(23)}$ investigaram a expressão da proteína p53 (clones DO-7 e PAb-240) em 348 tumores malignos da cavidade bucal, verificando que o anticorpo DO-7 mostrou-se mais expresso em intensidade e quantidade quando comparado ao PAb-240. Os resultados do presente estudo em associação aos estudos supracitados confirmam a identificação de sequências diferentes da proteína p53 por esses biomarcadores (clone DO-7 e PAb-240), e esse fato deve ser considerado na análise dos resultados imuno-histoquímicos. Sendo assim, a utilização de anticorpos que identificam a proteína nativa e/ou selvagem pode justificar em parte os resultados conflitantes na análise da imunoexpressão da proteína p53 nos CCEB, comumente observados nos estudos investigados.

Os avanços das técnicas de biologia molecular e a possibilidade de identificação de mutações no gene TP53 impulsionaram estudos com o objetivo de melhor compreender a participação desse gene no desenvolvimento e na progressão dos CCEB. Contudo, como a maioria das mutações encontrada no gene TP53 são mutações do tipo missense ${ }^{(37)}$, que ocasionam acúmulo da proteína alterada no núcleo das células, acredita-se que a expressão observada pela imuno-histoquímica seja reflexo das alterações nesse gene. Nesse sentido, o estudo de técnicas de análise de mutação no gene TP53 é necessário para confirmação de resultados obtidos com a técnica imuno-histoquímica, podendo assim 
determinar os melhores anticorpos a serem empregados e estimar o papel desse biomarcador no CCEB.

\section{Conclusões}

A partir dos resultados obtidos no presente estudo, foi possível observar que a expressão da proteína p53 é um evento comumente observado nos CCEB, tanto em localização intrabucal quanto labial, sugerindo a ocorrência de mutações no gene TP53. As diferenças quantitativas obtidas entre os anticorpos estudados, independentemente da localização das lesões, refletem uma especificidade distinta entre os clones DO-7 e PAb-240 em CCEB. O desenvolvimento de mais estudos será fundamental para estabelecer o anticorpo mais adequado para avaliação da proteína p53 em CCEB.

\section{Referências}

1. BARNES, L. et al. World Health Organization Classification of Tumours. Pathology and Genetics of Head and Neck Tumours. Lyon: IARC Press, 2005.

2. BELTRAMI, C.A.; DESINAN, L.; RUBINI, C. Prognostic factors in squamous cell carcinoma of the oral cavity. A retrospective study of 80 cases. Pathol Res Pract, v. 188, n. 4-5, p. 510-6, 1992.

3. BONSING, B.A. et al. Specificity of seven monoclonal antibodies against p53 evaluated with Western blotting, immunohistochemistry, confocal laser scanning microscopy, and flow cytometry. Cytometry, v. 28, n. 1, p. 11-24, 1997.

4. BOURDON, J.C. p53 and its isoforms in cancer. Br J Cancer, v. 97, n. 3, p. 277-82, 2007.

5. CAMISASCA, D.R. et al. Expression of $\mathrm{Bcl}-2$ family proteins and associated clinicopathologic factors predict survival outcome in patients with oral squamous cell carcinoma. Oral Oncol, doi: 10.1016/j.oraloncology.2 008.05.021, 2008(in pres.).

6. CASADO, S. et al. Predictive value of P53, BCL-2, and BAX in advanced head and neck carcinoma. Am J Clin Oncol, v. 25, n. 6, p. 588-90, 2002.

7. CHANG, C. et al. Identification and partial characterization of new antigens from simian vírus 40-transformed mouse cell. J Virol, v. 31, n. 2, p. 463-71, 1979.

8. CHO, Y. et al. Crystal structure of a p53 tumor suppressorDNA complex: understanding tumorigenic mutations. Science, v. 265, n. 5170, p. 334-5, 1994.

9. COSTA, A.L.L. et al. Correlação entre a classificação TNM, gradação histológica e localização anatômica em carcinoma epidermóide oral. Pesqui Odontol Bras, v. 16, n. 3, p. 216-20, 2002

10. COSTA, A.L.L., ARAÚJO JÚNIOR, R.F.; RAMOS, C.C.F. Correlação entre a classificação clínica TNM e as características histológicas de malignidade do carcinoma epidermóide oral. Rev Bras Otorrinolaringol, v. 71, n. 2, p. 181-7, 2005

11. CRUZ, I. et al. Specific p53 immunostaining patterns are associated with smoking habits in patients with oral squamous cell carcinomas. J Clin Pathol, v. 55, n. 11, p. 834-40, 2002.
12. FAN, G.K. et al. Immunohistochemical analysis of P57 (kip2), p53 and hsp60 expressions in premalignant and malignant oral tissues. Oral Oncol, v. 42, n. 2, p. 147-53, 2006.

13. FENOGLIO-PREISER, C.M. et al. TP53 and gastric carcinoma: a review. Hum Mutat, v. 21, n. 3, p. 25870, 2003

14. FRIEND, S. p53: A glimpse at the puppet behind shadow play. Science, v. 265, n. 5170, p.334-5, 1994.

15. GANNON, J.V. et al. Activating mutations in p53 produce a common conformational effect. A monoclonal antibody specific for the mutant form. EMBO J, v. 9, n. 5, p. 1595-602, 1990.

16. GARCÍA-MONTESINO-PEREA, B.; VAL-BERNAL J.F.; SAIZ-BUSTILLO, R. Epidermoid carcinoma of the lip: an immunohistochemical study. Med Oral Patol Oral Cir Bucal, v. 10, n. 5, p. 454-61, 2005.

17. GASCO, M.; CROOK, T. The p53 network in head and neck cancer. Oral Oncol, v. 39, n. 3, p. 222-31, 2003.

18. GONZALEZ-MOLES, M.A. et al. Differences in the expression of p53 protein in oral lichen planus based on the use of monoclonal antibodies DO-7 and PAb-240. Oral Oncol, v. 44, n. 5, p. 496-503, 2008.

19. HARLOZINSKA, A. et al. Relations between immunologically different p53 forms, p21(WAF1) and PCNA expression in ovarian carcinomas. Oncol Rep, v. 9, n. 6, p. 117379, 2002.

20. HIROTA, S.K. et al. Risk factors for oral squamous cell carcinoma in young and older Brazilian patients: A comparative analysis. Med Oral Patol Oral Cir Bucal, v. 13, n. 4, p. 227-31, 2008.

21. HORTA, M.C. etal. p53 and p21WAF1/CIP1 overexpression at the invasive front of lower lip squamous cell carcinoma. J Oral Pathol Med, v. 36, n. 2, p. 88-92, 2007.

22. INCA. Estimativa 2008 Incidência de câncer no Brasil. Disponível em: www.inca.gov.br/estimativa/2008. Acesso em: 20 abr. 2008.

23. JAYASURYA, R. et al. Phenotypic alterations in Rb pathway have more prognostic influence than p53 pathway proteins in oral carcinoma. Mod Pathol, v.18, n. 8, p. 1056-66, 2005. 
24. LANE, D.P.; CRAWFORD, L.V. T-antigen is bound to host protein in SV40-transformed cells. Nature, v. 278, n. 5701, p. 261-3, 1979.

25. LINZER, D. I.; LEVINE, A. J. Characterization of a $54 \mathrm{~K}$ dalton cellular SV40 tumor antigen present in SV4Otransformed cells and uninfected embryonal carcinoma cells. Cell; v. 17, n. 1, p. 43-52, 1979.

26. MA, L. et al. Clinical implication of screening p53 gene mutations in head and neck squamous cell carcinomas. $J$ Cancer Res Clin Oncol, v. 124, n. 7, p. 389-96, 1998.

27. MIDGLEY, C.A. et al. Analysis of p53 expression in human tumours: an antibody raised against human p53 expressed in Escherichia coli. J Cell Sci, v. 101 (Pt 1), p. 183-9, 1992.

28. MIGHELL, A. PCNA and p53. Eur J Cancer B Oral Oncol, v. 31B, n. 6, p. 403-4, 1995.

29. MOORE, S. et al. The epidemiology of lip cancer: a review of global incidence and aetiology. Oral Dis; v. 5, n. 3, p. 185-95, 1999.

30. NEVILLE, B.W.; DAY, T.A. Oral cancer and precancerous lesions. CA J Clinic, v. 52, n. 4, p. 195-215, 2002.

31. NYLANDER, K.; DABELSTEEN, E.; HALL, P.A. The p53 molecule and its prognostic role in squamous cell carcinomas of the head and neck. J Oral Pathol Med, v. 29, n. 9, p. 413-25, 2000.

32. OSTWALD, C. et al. p53 mutational spectra are different between squamous-cell carcinomas of the lip and the oral cavity. Int J Cancer, v. 88, n. 1, p. 82-86, 2000.

33. PARTRIDGE, M. et al. New insights into p53 protein stabilization in oral squamous cell carcinoma. Oral Oncol, v. 35, n. 1, p. 45-55, 1999.

34. SARANATH, D. et al. p53 inactivation in chewing tobaccoinduced oral cancers and leukoplakias from India. Oral Oncol, v. 35, n. 3, p. 242-50, 1999.

35. SATHYAN, K.M. et al. Carcinoma of tongue and the buccal mucosa represent different biological subentities of the oral carcinoma. J Cancer Res Clin Oncol, v. 132, n. 9, p. 601-9, 2006.

36. SCHOELCH, M.L. et al. Apoptosis-associated proteins and the development of oral squamous cell carcinoma. Oral
Oncol, v. 35, n. 1, p. 77-85, 1999.

37. SOUSSI, T. Focus on the p53 gene and cancer: advances in TP53 mutation research. Hum Mutat, v. 21, n. 3, p. 173-5, 2003.

38. SOUSSI, T. et al. Locus-specific mutation databases: pitfalls and good practice based on the p53 experience. Nat Rev Cancer, v. 6, n. 1, p 83-90, 2006.

39. STEPHEN, C.W.; HELMINEN, P.; LANE, D.P. Characterisation of epitopes on human p53 using phage-displayed peptide libraries: Insights into antibody peptide interactions. J Mol Biol, v. 48, n. 1, p. 58-78, 1995.

40. STEPHEN, C.W.; LANE, D.P. Mutant conformation of p53. Precise epitope mapping using a filamentous phage epitope library. J Mol Biol, v. 225, n. 3, p. 577-83, 1992.

41. TAYLOR, D. et al. Immunohistochemical detection of p53 protein accumulation in head and neck cancer: correlation with p53 gene alterations. Hum Pathol, v. 30, n. 10, p.1221-5, 1999.

42. THOMAS, M.D. et al. A novel quantitative immunoassay system for p53 using antibodies selected for optimum designation of p53 status. J Clin Pathol, v. 50, n. 2, p. 143-7, 1997.

43. VARLEY, J.M. Germline TP53 Mutations and Li-Fraumeni Syndrome. Hum Mutat, v.21, n. 3, p. 313-20, 2003.

44. VOGELSTEIN, B.; KINZLER, K.W. Cancer genes and the pathways they control. Nat Med, v. 10, n. 8, p. 78999, 2004.

45. VOJTËSEK, B. et al. An immunochemical analysis of the human nuclear phosphoprotein p53. New monoclonal antibodies and epitope mapping using recombinant p53. J Immunol Methods, v. 151, n. 1-2, p. 237-44, 1992.

46. VOUSDEN, K.H.; LANE, D.P. p53 in health and disease. Nat Rev Mol Cell Biol, v. 8, n. 4, p. 275-83, 2007.

47. YAMAZAKI, Y. et al. Specific p53 mutations predict poor prognosis in oral squamous cell carcinoma. Oral Oncol, v. 39, n. 2, p. 163-9, 2003.

48. YOLCU, E. et al. A monoclonal antibody against DNA binding helix of p53 protein. Oncogene, v. 20, n. 11, p. 1398-401, 2001.
Endereço para correspondência

Professora Simone de Queiroz Chaves Lourenço Departamento de Patologia - Hospital Universitário Antônio Pedro

Rua Marquês de Paraná, $303-4^{\circ}$ andar CEP: $24033-900$ - Niterói-R] e-mail: mpts@@vm.uff.br/silourenco@br.inter.net 